14

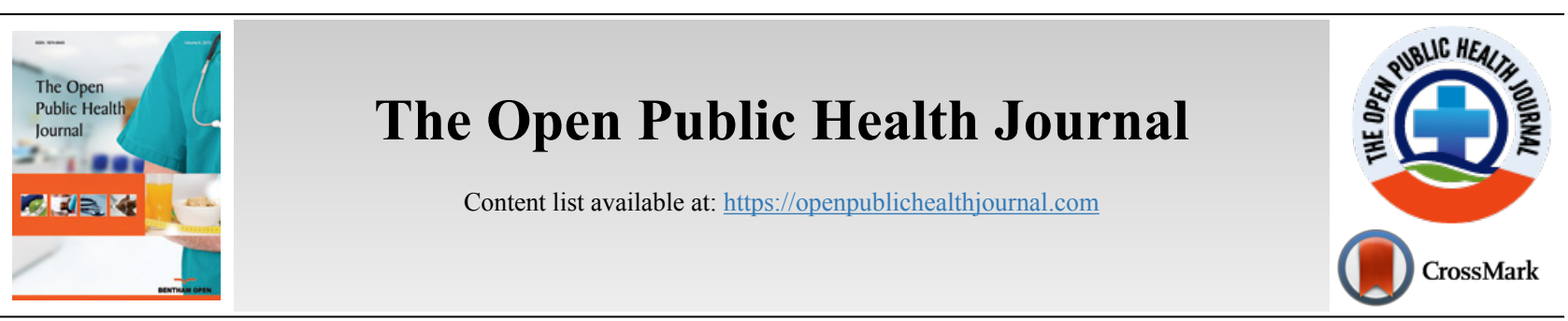

RESEARCH ARTICLE

\title{
Causes of Deaths in Northern Cyprus: Implications for Accurate Recording and Prevention of Deaths
}

\author{
Macide Artac Ozdal ${ }^{1, *}$ and Seda Behlul ${ }^{1,2}(\mathbb{D})$ \\ ${ }^{1}$ Department of Health Management, Faculty of Health Sciences, European University of Lefke, Lefke, Northern Cyprus, TR-10 Mersin, Turkey \\ ${ }^{2}$ Department of Health Management, Faculty of Health Sciences, Near East University, Near East Boulevard, Nicosia, Northern Cyprus, TRNC \\ Mersin 10, Turkey
}

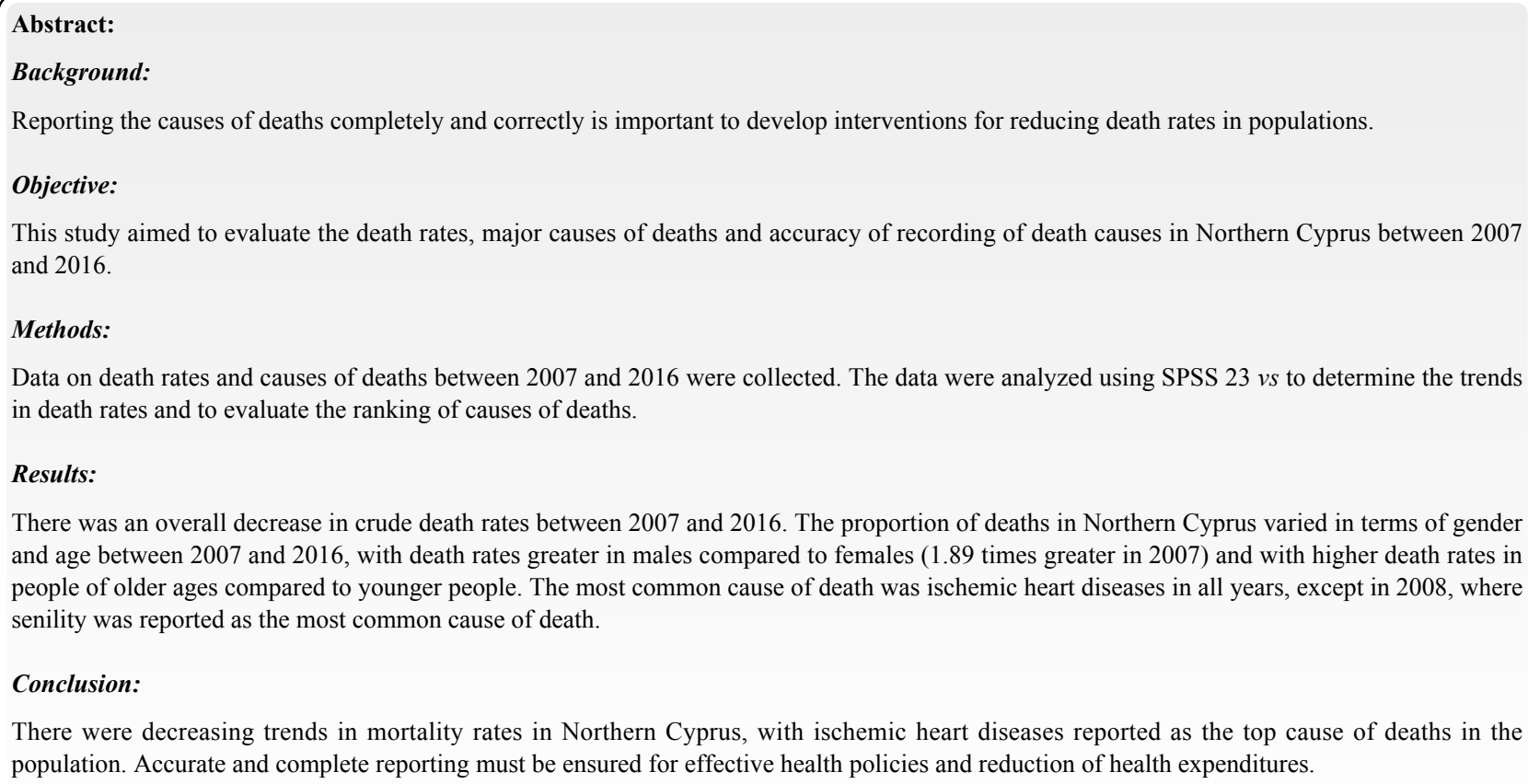

There was an overall decrease in crude death rates between 2007 and 2016. The proportion of deaths in Northern Cyprus varied in terms of gender and age between 2007 and 2016, with death rates greater in males compared to females (1.89 times greater in 2007) and with higher death rates in people of older ages compared to younger people. The most common cause of death was ischemic heart diseases in all years, except in 2008 , where senility was reported as the most common cause of death.

\section{Conclusion:}

There were decreasing trends in mortality rates in Northern Cyprus, with ischemic heart diseases reported as the top cause of deaths in the population. Accurate and complete reporting must be ensured for effective health policies and reduction of health expenditures.

Keywords: Accuracy, Causes, Mortality rate, North Cyprus, Reporting, Trends.

\begin{tabular}{|l|l|l|r|}
\hline Article History & Received: October 12, 2019 & Revised: December 18, 2019 & Accepted: December 30, 2019
\end{tabular}

\section{INTRODUCTION}

It is important to evaluate rates and causes of deaths using statistical information in order to develop and/or improve interventions and health policies to reduce death rates due to specific causes $[1,2]$. It is therefore crucial to have accurate and quality recording of causes of deaths for accurate assessment of deaths rates. In addition to the causes of deaths,

* Address correspondence to this author at the Department of Health Management, Faculty of Health Sciences, European University of Lefke, Lefke, Northern Cyprus, TR-10 Mersin, Turkey; Tel: +905488652606;

E-mail: mozdal@eul.edu.tr the demographic information of deceased people must also be accurately recorded to enable the assessment of the characteristics of those dying from specific causes and at different times.

There has recently been an enhancement in information technology systems, which play an important role in improving the recording of deaths and their causes [3]. There are inequalities in the recording of causes of deaths in countries with different income levels. High-income countries have developed systems for determining the causes of deaths correctly and have accurate records of deaths. However, low 
and middle-income countries are experiencing difficulties in accurately determining the causes of deaths and the number of deaths. This is because of the poor recording of the number and causes of deaths in such countries, which is predominantly due to the absence of functional electronic medical recording systems [4, 5]. It is important to improve the recording of causes of deaths to develop policies and interventions to reduce preventable deaths [6].

Mortality rates for the global population are available for 2016 and adult mortality, which is defined as the likelihood of a 15 -year-old dying before reaching the age of 60 , was 142 per 1000 population on average. The adult mortality rates are higher in low-income regions compared with other regions of the world, with the African region ranked as the highest since 2000 [7]. More than half of all deaths observed in 2016 were attributable to the leading 10 causes of death worldwide, with ischaemic heart disease and stroke as the first two causes of deaths [4]. The majority of deaths globally are caused by noncommunicable diseases [5]. The literature regarding the changes in causes of deaths shows that there was a remarkable increase in deaths due to non-communicable diseases from 2005 to 2015, with a reduction in age-standardized death rates. Deaths attributable to communicable diseases, maternal or neonatal problems or undernutrition have, however, decreased in the same time period, where this decline was largely due to a decrease in deaths caused by diseases, such as HIV/AIDS, malaria and preterm birth complications [8]. Ischaemic heart diseases and strokes have remained the leading causes of deaths since 1990, and infectious diseases such as lower respiratory infections, diarrhoeal diseases, tuberculosis and HIV/AIDS have been on the decline, with fewer deaths today compared to the past [5]. The trends in the causes of deaths further show that diabetes caused more deaths compared to the previous decade, with 1 million more deaths attributable to diabetes observed in 2016 compared to 2000. Dementia was also shown to have caused two times more deaths in 2016 compared to 2000 , ranking $14^{\text {th }}$ in 2000 , and $5^{\text {th }}$ in 2016 among all causes of death [4].

Cyprus is an island in the Eastern Mediterranean region. The island has politically been governed in two parts separated as Northern and Southern Cyprus. In Northern Cyprus, health services are provided predominantly by public hospitals, with an increasing usage of health care services in private hospitals observed in recent years. In 2016, the Gross Domestic Product (GDP) in Northern Cyprus was reported as 3.837.9 GDP Million \$, with a real growth rate of 3.6\%. Gross National Product (GNP) per capita was also reported as $\$ 13.902$ also in 2016 [9]. There is limited evidence on the health status and health outcomes of the population living in Northern Cyprus. The available evidence showed that age standardized total cancer mortality rates accounted for $9 \%$ of all deaths observed between 1995 and 2007 [10]. In another study, it was reported that the suicide rate was $2.79 \%$ per 100000 population in 2013 [11]. In a study assessing the mortality due to cerebrovascular diseases, it was observed that ischemic stroke and intracerebral hemorrhage accounted for $26.6 \%$ and $11.25 \%$ of all deaths that occurred in 2014 in the region [12]. In 2016, it was shown that the crude date rate was 4.6 per 1000 population and the infant mortality rate was 0.8 per 1000 live births [9].

Health policies must be based on evidence developed using data on the health status of populations. Statistical information using data on the health outcomes are, therefore, very important for introducing health policies for the promotion of health in communities. Death, as the last outcome of various health problems, is an important measure for determining health problems affecting populations [2]. A further advantage of using mortality data is that it is easy to define and the majority of nations are reporting them as vital statistics [13]. Vital statistics make it mandatory to report deaths to the government and such records include information such as name, age at death and cause of death. The causes of deaths are required to be recorded through a death certificate prepared by a physician [2]. Accurate recording of causes of death carries importance for the accurate evaluation of health status in populations [3]. This requires physicians, interns and medical students to be trained on the accurate determination and recording of death causes $[14,15]$. There is also evidence that training should be given to funeral directors on the accurate recording of demographic information on the deceased [13].

There is an international coding system called the International Classification of Diseases (ICD) which provides standardized coding of causes of deaths on death certificates around the world. The aim of this standardized coding is to make the statistics comparable between different regions. Most developed countries are using this system [2]. The most recent version of the ICD coding system being followed is ICD-11 [16].

The burden of disease on the populations can be measured by the crude measurement of death rates, cause-specific death rates, gender-specific death rates, child mortality rates and others. These measures provide superficial information on the mortality level in populations. However, they offer limited insights into the health problems leading to disability in communities, which is also another measure affecting disease burden. For this reason, Disability Adjusted Life Years (DALY), which combines morbidity and mortality, is used to give a more comprehensive picture of health in a population [17].

In the history of the assessment of mortality data, ranking specific causes of death has been one of the most preferred methods [18]. Ranking the causes of death is a method that provides information about the relative impact of various causes of death. It is important to note that ranking specific causes has limitations and it does not demonstrate the risk attributable to different causes. For example, although the ranking of deaths due to specific causes varies with age, the mortality rate due to other causes may not change [19].

This study aims to evaluate the trends in mortality and to determine the specific causes of deaths in the North Cyprus population between the years 2007 and 2016. The study also aims to examine the trends in age-specific death rates and changes in the causes of deaths in the specified time period. 
Table 1. Descriptive statistic of number of deaths.

\begin{tabular}{|c|c|c|c|}
\hline Variables & Minimum & Maximum & Mean \pm std \\
\hline The number of deaths in females & 418.00 & 537.00 & $474.9 \pm 41.49$ \\
\hline The number of deaths in males & 530.00 & 671.00 & $586 \pm 43.04$ \\
\hline The total number of deaths & 960.00 & 1177.00 & $1060.9 \pm 76.05$ \\
\hline
\end{tabular}

\section{MATERIALS \& METHODS}

\subsection{Data Collection}

This study uses a descriptive time-trend study design, which is a form of longitudinal ecological study, with the aim of analyzing the trends in the death rates and causes of deaths between the years of 2007 and 2016. Ecological data on the total number of deaths, number of deaths in different genders and ages, and the causes of deaths observed between the years from 2007 to 2016 were collected from the statistical yearbooks of the Prime Ministry State Planning Organization of Northern Cyprus (SPO, 2018) [20].

De-jure population numbers were also collected from the records of the State Planning Organization to determine death rates per 10,000 persons. De-jure populations determined at the censuses in 2006 and 2011 were used for determining the mortality rates between 2007 and 2016. The population number was 256,644 according to the census conducted in 2006 and this was used for the calculation of death rates between 2006 and 2010. The population number according to the 2011 census was 286,257, which was used for calculation of density for 2011. After 2012, projected population numbers were taken from the 2016 yearbook of the State Planning Organization, which were used for calculating the death rates in the years between 2012 and $2016(297,608,306,368,320,884,331,432$ and 339,478 , respectively).

\subsection{Research Questions and Significance of the Study}

The research questions and motivation factors were determined as follows:

- What are the most commonly reported causes of deaths in Northern Cyprus?

- How have the causes of deaths changed over the years?

- How have the causes of deaths changed between age groups over the years?

The study will help in the determination of health policies for the prevention of deaths by:

- Providing information about the health status of the population.

- Providing evidence to the literature about the health in Northern Cyprus, since there is lack of studies reporting on health for the North Cyprus population.

\subsection{Data Analysis}

In the study, secondary data was used to analyze the trends in death rates between 2007 and 2016, causes of deaths, number of deaths in different genders, and distribution of deaths by age groups and by years. The crude death rates were calculated using the population number based on the population numbers determined in the censuses and the projections based on the population growth. The age-specific death rates and gender-specific death rates were also determined based on the number of deaths each year per the population in specific age and gender groups. Univariate analyses were first performed to determine the characteristics of the variables using descriptive statistics. Graphical plots displaying the data over the time period from 2007 and 2016 were used to assess the changes in the crude death rates and the causes of deaths between the years of 2007 and 2016. The statistical analysis in this study was performed by using Statistical Package for Social Science (SPSS vs 23).

\section{RESULTS}

A total of 10,555 deaths (4,749 males and 5,806 females) were recorded between 2007 and 2016 at the Prime Ministry State Planning Organization (SPO). The descriptive statistics of the number of deaths and the proportion of deaths according to gender are presented in Table 1. There was a total of 1060.9 \pm 76.05 deaths between 2007 and 2016. The total number of deaths in males was $586 \pm 43.04$ and in females was $474.9 \pm 41.49$.

The crude death rates were 37.79 per 10,000 population in 2007, with 34.67 per 10,000 population in 2016 (Table 2). While the total number of deaths increased per year, crude death rates decreased compared to the death rates in previous years. The trends in crude death rates are shown in Fig. (1). While the total number of deaths was 1,165 in 2015 and 1,177 in 2016 , the crude death rates were 35.15 per 10,000 population in 2015 and 32.18 per 10,000 population in 2016 . Although there was an increasing trend in crude death rates from 2007 to 2011 (37.79 per 10,000 in 2007 and 40.55 per 10,000 in 2011), there was a sharp decrease in crude death rates after 2011 (36.76 per 10,000 in 2011 compared to 34.67 per 10,000 in 2016).

Gender specific deaths rates and trends in death rates between the years of 2007 and 2016 are given in Table $\mathbf{2}$ and Fig. (2). The total number of deaths was 1,177 was 2016 , which was an increase of $12(1.03 \%)$ compared to 2015 . The total number of deaths among males was 671 , which showed an increase of $6.84 \%$ in males and a decrease of $-5.77 \%$ in females. The male death rate was higher compared to the female death rate in 2016 (per 10,000 population). The crude death rate comparison between 2015 and 2016 showed an increase in death rates by $4.07 \%$ for men and a decrease by $-7.76 \%$ for women.

The proportions of deaths out of the total deaths in Northern Cyprus according to different genders were studied 
and are shown in Fig. (3). A higher proportion of males died in each year compared to females. The crude death rate among men was 1.89 times higher compared to women in 2007 (Table 2). The gap between the rate of deaths of men and women declined, with the crude death rate among men 1.14 higher compared with women in 2016.

The death rates according to age groups by years were evaluated separately and are given in Table 3 . The comparison of the change in death rates between 2015 to 2016 showed that the death rates decreased overall $(-1.36 \%)$, with a decrease of $-19.6 \%$ in the $25-34$ age group, $-10.4 \%$ in the $45-54$ age group and $-0.27 \%$ in those aged 75 years and over. When the deaths rates were analyzed for other age groups, increases in death rates were mainly observed in the 15 to 24 year age group (94.1\%), followed by the 35 to 44 age group (35.1\%), 5 to 14 age group (33.3\%) and 0 to 4 age group (20.8\%).

The records on the causes of deaths were analyzed to show the ranking in the causes of deaths which are shown in Fig. (4). The results showed that ischemic heart disease was the leading cause of death in the majority of the year between 2007 and 2016. Ischemic heart diseases were markedly reported as the leading cause of death, particularly after 2010, whilst senility was also largely reported as the cause of death in the years between 2007 and 2010 (Fig. 4). In 2007, while 31.78\% of all deaths were attributed to ischemic heart diseases, $27.55 \%$ of them were reported to be due to senility and $15.06 \%$ of deaths were caused by cancer. In total, these causes accounted for $74.39 \%$ of the total mortality rate in 2007 . In 2008 , the leading cause of death was reported as senility, with $38.02 \%$ of all deaths caused by senility, followed by ischemic heart diseases (27.18\%) and cancer (13.08\%). In 2009 and 2010, the three leading causes of deaths were found to be ischemic heart diseases, senility and cancer, respectively. From 2011 to 2012, increases were found in the rates of ischemic heart diseases $(6.91 \%)$, lung diseases $(0.58 \%)$, while decreases were observed for senility $(-4.64 \%)$ and cancer $(-2.15 \%)$. Ischemic heart diseases were reported as the leading cause of death in 2013 and 2014. From 2015 to 2016, increases in the death rates were found for ischemic heart diseases (1.93\%), cancer $(2.72 \%)$ and senility $(1.5 \%)$, while a decrease was found in diseases of the lungs and shortness of breath. A small proportion of deaths were attributable to cerebrovascular diseases (including stroke) in all years of the study period. For example, $4.23 \%$ of deaths were attributable to cerebrovascular diseases in 2007, whilst only $1.87 \%$ of deaths were due to cerebrovascular diseases in 2016. There was an increase in the proportion of deaths due to cerebrovascular diseases from 2010 to 2013 (from $2.37 \%$ to $4.84 \%$ ) and it then declined from 2013 until 2016.

\section{DISCUSSION}

\subsection{Main Findings of the Study}

The analysis of the cause of death is very critical for identifying public health priorities and assessing the effectiveness of health programs. Accurate reporting and evaluation of data are important in the decision process. Multidisciplinary work is therefore required to improve the reporting of deaths. Implementation of data quality controls is essential for improving reporting. In our study, we proposed to explore the causes of deaths in Northern Cyprus. A total of 10,555 deaths were recorded between 2007 and 2016, in the Prime Ministry SPO. The crude death rate was 34.67 and death rates were higher in males compared with females in 2016. Death rates were analyzed for age groups, where increases were observed in the early years the 15 to 24 year age group. The leading cause of mortality in the region was reported as senility in previous years, with increased rates of ischemic heart diseases and cancer reported in more recent years.

\subsection{Explanation and Comparison with Existing Literature}

It is important to study the mortality rates and the causes of deaths in epidemiological research. There is a strong evidence showing the importance of the evaluation of ill-defined coding and unknown causes of death to pay attention to the availability and accuracy of the data, as it is a key factor in the assessment of health status and the establishment of health policies [21]. In this study, there was a decline in crude death rates in most of the age groups between 2011 and 2016, which is comparable to the literature that shows a significant decline in death rates in the majority of age groups studied [22]. However, there was an increase in death rates in Northern Cyprus between 2007 and 2011, similar to trends revealed in a study conducted in Turkey between 2009 and 2016 [23].

In the current study, the crude death rate was determined to be higher in males compared to females throughout the study period. There is evidence supporting the fact that men die earlier compared to women, particularly in the developed parts of the world [24, 25]. The risk of dying may be different based on the diseases that different genders suffer. For example, whilst men have a greater risk of dying from circulatory diseases and lung cancer, women tend to die more of endocrine system diseases or inflammatory diseases [26].

It is important to monitor changes in health and disease status in populations in order to evaluate the effectiveness of public health practices and interventions [27, 28]. Ischemic heart disease was reported to account for a large proportion of deaths in the population throughout the study period, which is also a top cause of death observed around the world [5]. Senility was also reported as the most frequently observed reason for death in the population in the first years of the study period, but the frequency of senility-related deaths declined later in the period. Deaths related to neurodegenerative reasons can be reported as "senility" or "old-age", but deaths occurring in the older ages are more attributable to chronic diseases, such as stroke, heart diseases or cancer [29]. The increased rate of senility in the early years of the study period may be explained by the failure of healthcare professionals to identify chronic diseases as the reason of death. Senility may also have frequently been selected as the cause of death because further investigation by autopsy was not a preferred method in the reporting of death causes in elderly individuals. The decline in the reporting of senility as death cause may be attributable to improvements in technology and medical reporting and also the fact that health care professionals are now following more evidence-based medicine referring to guidance. 


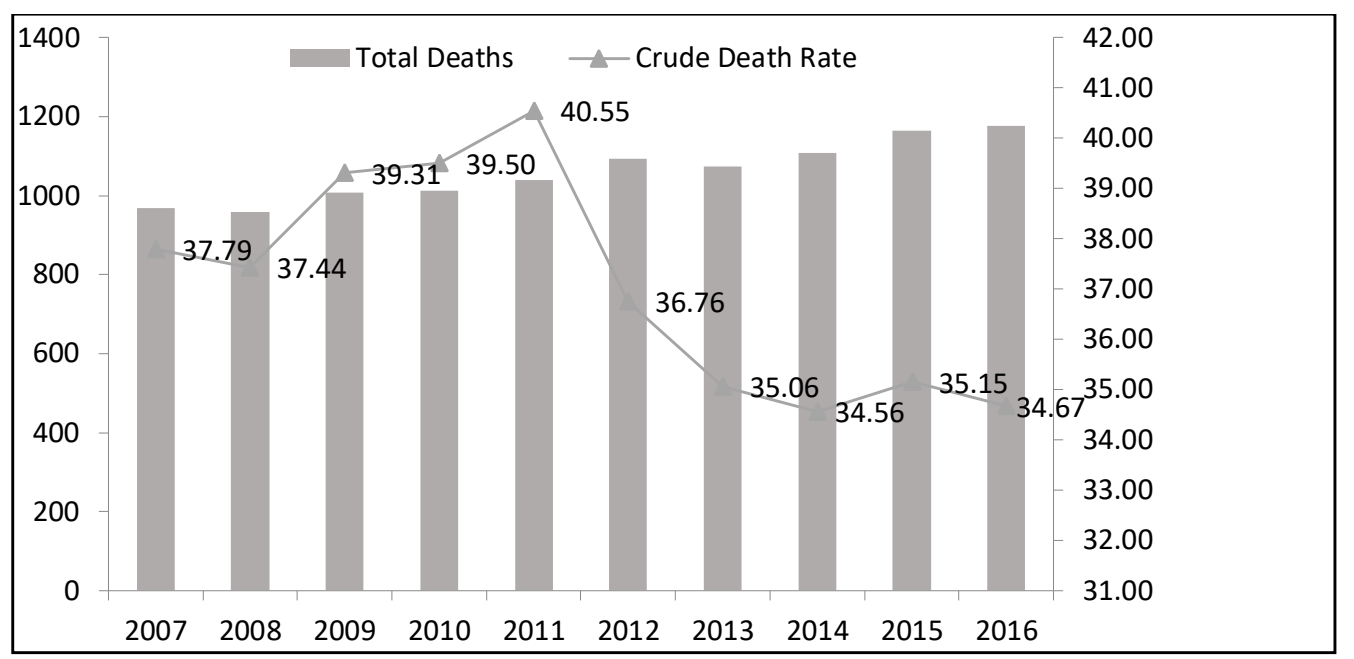

Fig. (1). Trends in the number of deaths and crude deaths rate from 2007 to 2016.

Table 2. Trends in number of deaths and crude deaths rates (in 10,000 population) from 2007 to 2016

\begin{tabular}{|c|c|c|c|c|c|c|c|}
\hline \multirow[b]{2}{*}{ Year } & \multirow[b]{2}{*}{ Total } & \multicolumn{2}{|c|}{ Number of deaths } & \multicolumn{2}{|c|}{ Crude death rate } & \multirow[b]{2}{*}{ Female } & \multirow[b]{2}{*}{$\begin{array}{c}\text { Sex ratio } \\
\text { (male/ } \\
\text { female) }\end{array}$} \\
\hline & & Male & Female & Total & Male & & \\
\hline 2007 & 969 & 551 & 418 & 37.79 & 36.62 & 30.79 & 1.89 \\
\hline 2008 & 960 & 534 & 426 & 37.44 & 35.49 & 31.38 & 1.13 \\
\hline 2009 & 1008 & 578 & 430 & 39.31 & 38.41 & 31.67 & 1.21 \\
\hline 2010 & 1013 & 530 & 483 & 39.50 & 35.22 & 35.57 & 0.99 \\
\hline 2011 & 1040 & 583 & 457 & 40.55 & 38.74 & 33.66 & 1.15 \\
\hline 2012 & 1094 & 581 & 513 & 36.76 & 36.96 & 36.53 & 1.01 \\
\hline 2013 & 1074 & 604 & 470 & 35.06 & 37.21 & 32.63 & 1.14 \\
\hline 2014 & 1109 & 600 & 509 & 34.56 & 35.05 & 34.00 & 1.03 \\
\hline 2015 & 1165 & 628 & 537 & 35.15 & 35.38 & 34.89 & 1.01 \\
\hline 2016 & 1177 & 671 & 506 & 34.67 & 36.82 & 32.18 & 1.14 \\
\hline Change & 12 & 43 & -31 & -0.48 & 1.44 & -2.71 & - \\
\hline $\begin{array}{c}\% \\
\text { change }\end{array}$ & 1.03 & 6.84 & -5.77 & -1.36 & 4.07 & -7.76 & - \\
\hline
\end{tabular}

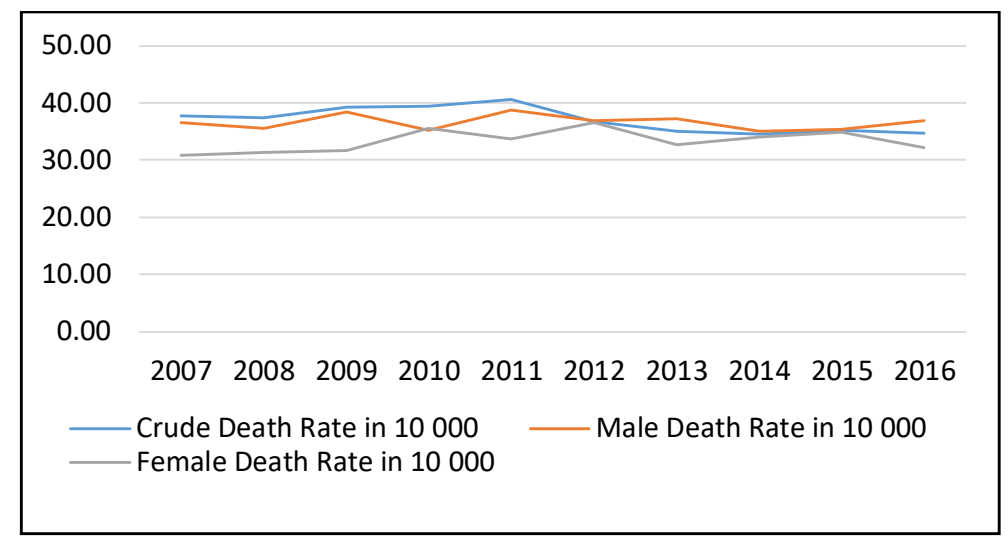

Fig. (2). Crude deaths rates and gender specific deaths rates in Northern Cyprus. 


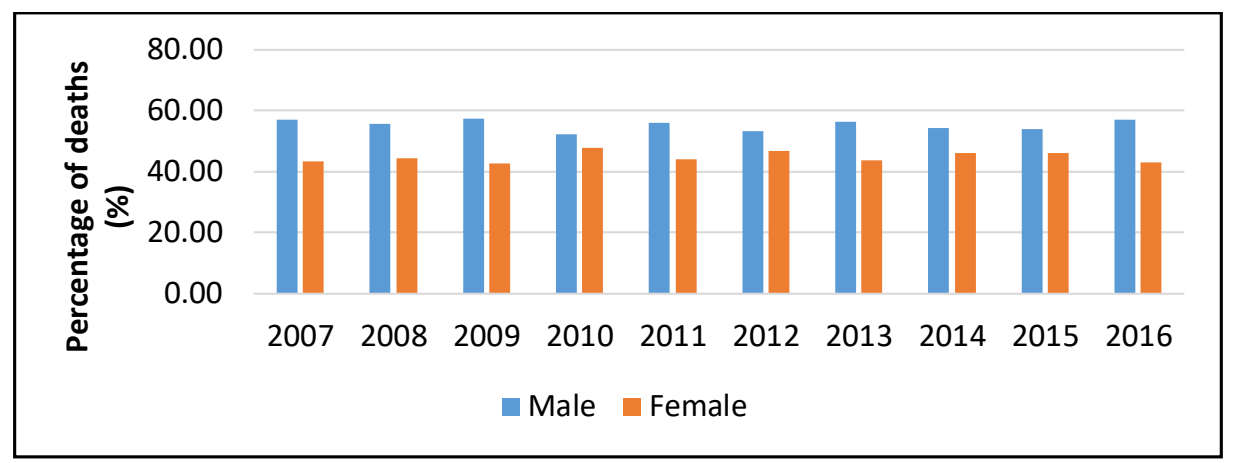

Fig. (3). Proportion of deaths in Northern Cyprus in different genders.

Table 3. Trends of death rates (in 10,000 population) by age from 2007 to 2016.

\begin{tabular}{|c|c|c|c|c|c|c|c|c|c|c|}
\hline \multicolumn{11}{|c|}{ Age (years) } \\
\hline Year & Total & $0-4$ & $5-14$ & $15-24$ & $25-34$ & $35-44$ & $45-54$ & $55-64$ & $65-74$ & +75 \\
\hline 2007 & 37.79 & 0.27 & 0.34 & 0.24 & 0.52 & 0.80 & 1.67 & 3.84 & 4.29 & 14.42 \\
\hline 2008 & 37.44 & 0.17 & 0.03 & 0.45 & 0.62 & 0.90 & 1.99 & 4.26 & 4.76 & 18.89 \\
\hline 2009 & 39.31 & 0.20 & 0.10 & 0.48 & 0.38 & 1.11 & 2.16 & 4.19 & 4.68 & 20.29 \\
\hline 2010 & 39.50 & 0.59 & 0.13 & 0.45 & 0.52 & 1.71 & 3.49 & 4.29 & 4.79 & 17.53 \\
\hline 2011 & 40.55 & 0.45 & 0.17 & 0.48 & 0.55 & 0.59 & 1.85 & 3.80 & 3.80 & 21.62 \\
\hline 2012 & 36.76 & 0.33 & 0.10 & 0.36 & 0.40 & 0.87 & 1.98 & 4.70 & 4.70 & 20.96 \\
\hline 2013 & 35.06 & 0.45 & 0.06 & 0.32 & 0.71 & 0.78 & 2.05 & 4.56 & 4.56 & 19.84 \\
\hline 2014 & 34.56 & 0.24 & 0.09 & 0.34 & 0.40 & 0.90 & 1.62 & 3.92 & 3.92 & 20.56 \\
\hline 2015 & 35.15 & 0.24 & 0.06 & 0.06 & 0.51 & 0.54 & 1.44 & 3.71 & 3.71 & 21.51 \\
\hline 2016 & 34.67 & 0.29 & 0.08 & 0.38 & 0.41 & 0.73 & 1.29 & 3.97 & 3.97 & 21.44 \\
\hline Change & -0.48 & 0.05 & 0.02 & 0.32 & -0.1 & 0.19 & -0.15 & 0.26 & 0.26 & -0.06 \\
\hline Per Change & -1.36 & 20.8 & 33.3 & 94.1 & -19.6 & 35.1 & -10.4 & 7.0 & 7.0 & -0.27 \\
\hline
\end{tabular}

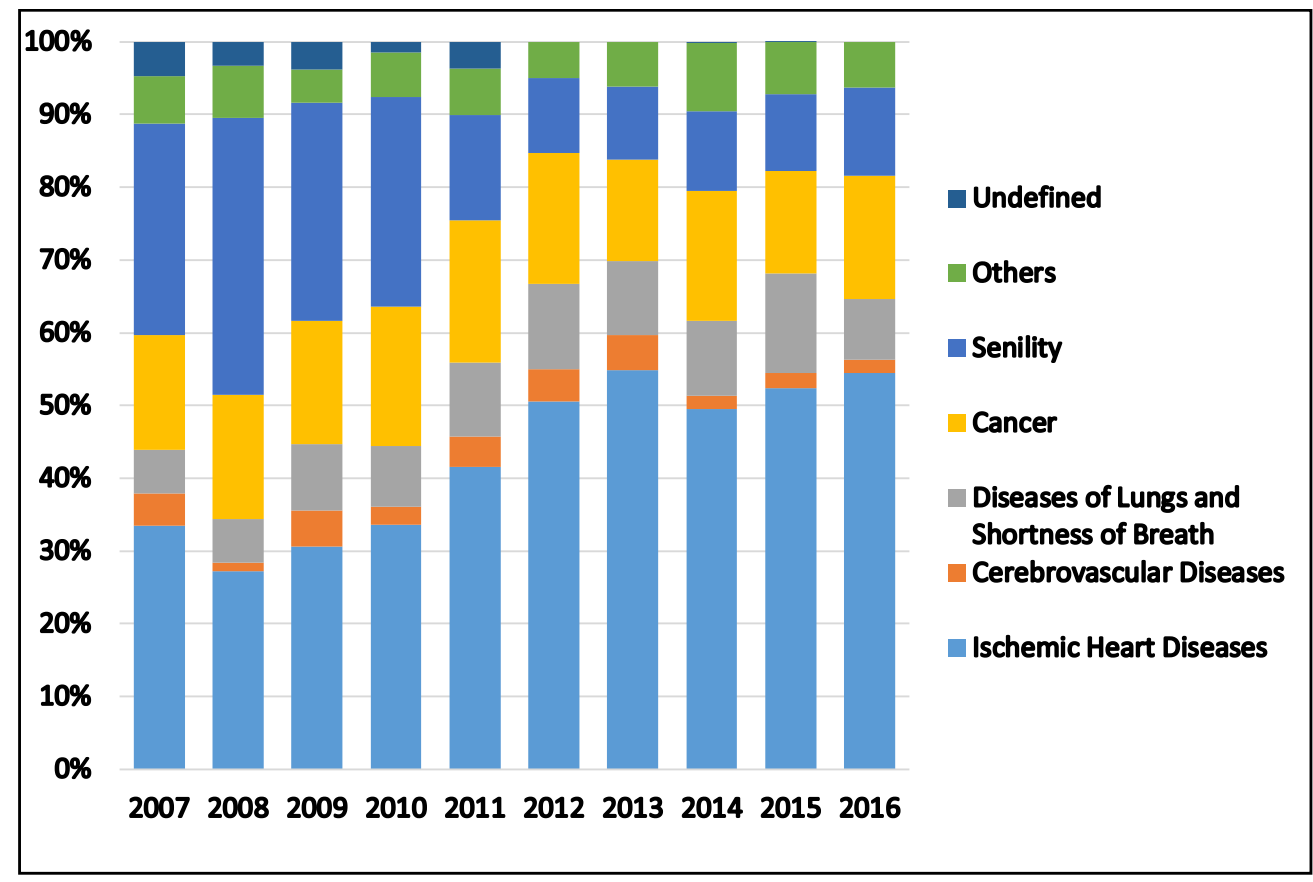

Fig. (4). Percentage of causes of deaths in Northern Cyprus between 2007 and 2016. 
The proportion of deaths due to cerebrovascular diseases formed a small proportion of the total deaths in the region. This is opposite to the world average, where cerebrovascular diseases rank second in the leading cause of death around the world [5]. Although the proportion of deaths reported due to cerebrovascular diseases was small, the results indicate that there was an increase in cerebrovascular disease deaths from 2010 to 2013. This is in line with evidence from North Cyprus that showed an increase in the percentage of patients who died after having a stroke between 2009 and 2011 [12]. Cerebrovascular diseases may lead to cognitive impairment, dementia or Alzheimer's disease, or the symptoms caused by cerebrovascular diseases can be confused with diseases of the elderly (dementia or Alzheimer's) [30]. This might lead to healthcare professionals to falsely report deaths from cerebrovascular diseases as senility. It is particularly important to assess cases, where senility is recorded as the cause of death and healthcare professionals must be trained on the accurate reporting of deaths $[15,31]$.

\subsection{Limitations of the Study}

The study used ecological data and collective data for the whole population and no individual-based data were employed in the study. In the case of limited resources for collecting individual data from records or by doing surveys, ecological data are advantageous for quickly and inexpensively collecting information about the healthcare status of populations, such as in this study for reporting the death rates and causes of deaths in a population. However, while ecological data give overall information for the total populations, the findings are not applicable to individuals. These types of studies are therefore prone to ecological fallacy, which assumes that all individuals in a population have similar characteristics. Furthermore, ecological data does not make it possible to analyze correlations between dependent and independent variables [32]. The data on deaths and causes of deaths were collected from vital recording systems. In developing regions in particular, vital registration systems may not be accurate and international recording systems (e.g. ICD-10) may have not been considered when deaths and their causes were recorded. In such vital registration systems, the records on the causes of deaths may also not be completed $[13,15]$. These factors may reduce the accuracy of the findings obtained using vital statistics data used to evaluate death rates and their causes in this study. Population projections were used to calculate crude deaths; however, population projections were not complete for all years in the study period (there were no projections until 2011). This may have affected the crude death rates calculated for the early years of the study period, where an increase in death rates was seen between 2007 and 2011. This could mean that there were actually no increases in the death rates as observed in the study.

\section{CONCLUSION}

Determining the causes of death and mortality is an important health indicator for the distribution of resources and for monitoring the impact of public health practices on mortality rates and the health status of population groups. Crude death rates declined between 2007 and 2016 in the population, with higher crude death rates in males compared to females. Ischemic heart disease was reported as the leading cause of death among the population in most of the study years. Senility, a term used to explain deaths occurring due to old age, was frequently recorded in the vital registration records of Northern Cyprus in the first years of the study period, although this declined in the later years of the study period. Senility should not be widely recorded as a cause of death, since the majority of such deaths occur due to chronic conditions, such as heart disease or stroke. Death statistics in Northern Cyprus are therefore not very accurate, although there have been some improvements in the recording of death causes. Accurate and complete reporting of death statistics is a factor that can affect public health through the development of effective health policies and the reduction of health expenditures. It is important to train and provide guidelines to those healthcare professionals who are responsible for recording death causes and to encourage the use of ICD systems for the accurate evaluation of causes of deaths.

\section{ETHICS APPROVAL AND CONSENT TO PARTI- CIPATE}

Not applicable.

\section{HUMAN AND ANIMAL RIGHTS}

No animals or humans were used for studies that are the basis of this research.

\section{CONSENT FOR PUBLICATION}

Not applicable.

\section{AVAILABILITY OF DATA AND MATERIALS}

The data supporting the findings of the article is available in the statistical yearbooks of Prime Ministry State Planning Organization of Northern Cyprus at URL: http://www.devplan .org/Frame-tr.html.

\section{FUNDING}

None.

\section{CONFLICT OF INTEREST}

The authors have no conflicts of interest that may have influenced either the conduct or the presentation of the research.

\section{ACKNOWLEDGEMENTS}

Data used in this study were taken from the report of the Prime Ministry State Planning Organization Statistics and Research Department. We would like to express our gratitude to the Prime Ministry of the Turkish Republic of Northern Cyprus for providing the data used in this study.

\section{REFERENCES}

[1] Egidi V, Buratta V. Information systems for health policies. In: Demography. Analysis and synthesis. Ed, G Caselli, J Vallin, G Wunsch. San Diego: Academic Press. 2006; p. 249-260..

[2] Wunsch G, Gourbin C. Mortality, morbidity and health in developed societies: A review of data sources. Genus 2018; 74(1): 2-27. 
[http://dx.doi.org/10.1186/s41118-018-0027-9] [PMID: 29398718]

[3] Lefeuvre D, Pavillon G, Aouba A, et al. Quality comparison of electronic versus paper death certificates in France, 2010 Popul Health Metr 2014; 12(1): 3 .

[http://dx.doi.org/10.1186/1478-7954-12-3] [PMID: 24533639]

[4] World Health Organization. (2018) The top 10 causes of death 2018 factsheet.. Available from: https://www.who.int/news-room/fact-sheets/detail/the-top-10-causes-o f-death

[5] Naghavi M, Abajobir AA, Abbafati C, et al. GBD 2016 Causes of Death Collaborators. Global, regional and national age-sex specific mortality for 264 causes of death, 1980-2016: A systematic analysis for the Global Burden of Disease Study 2016. Lancet 2017; 390(10100): 1151-210

[http://dx.doi.org/10.1016/S0140-6736(17)32152-9] [PMID: 28919116]

[6] Kochanek KD, Murphy SL, Xu J, Tejada-Vera B. Deaths: Final data for 2014. Natl Vital Stat Rep 2016; 65(4): 1-122. [PMID: 27378572]

[7] World Health Organization.(2019) Global Health Observatory (GHO) data.. Available from: https://www.who.int/gho/mortality_burden_disease/mortality_adult/sit uation trends text/en/

[8] Wang H, Naghavi M, Allen C, et al. GBD 2015 Mortality and Causes of Death Collaborators. Global, regional and national life expectancy, all-cause mortality, and cause-specific mortality for 249 causes of death, 1980-2015: A systematic analysis for the Global Burden of Disease Study 2015. Lancet 2016; 388(10053): 1459-544.

[http://dx.doi.org/10.1016/S0140-6736(16)31012-1] [PMID: 27733281]

[9] State Planning Organization Statistics and Research Department, (2016). Economic and Social Indicators. URL: Available from: http://www.devplan.org/Ecosos/BOOK/SEG-2016.pdf

[10] Hinçal E. Cancer mortality in north cyprus 1995-2007. Indian J Med Sci 2016; 68(1): 31-5.

[http://dx.doi.org/10.18203/issn.0019-5359.IndianJMedSci20163528]

[11] Sonmez I, Bozkurt A, Akbirgun A. Suicide rate in a mediterranean island: North cyprus. J Psychiatry 2015; 18(273): 2.

[12] Selçuk F, Mut S, İncirli SU, et al. Stroke incidence, risk factors and mortality rates in northern cyprus. Turkiye Klinikleri J Neur 2014; 9(1): 1-8.

[13] Hahn RA, Wetterhall SF, Gay GA, et al. The recording of demographic information on death certificates: A national survey of funeral directors. Public Health Rep 2002; 117(1): 37-43.

[http://dx.doi.org/10.1016/S0033-3549(04)50106-1] 12297680]

[PMID: McAllum C, St George I, White G. Death certification and doctors' dilemmas: A qualitative study of GPs' perspectives. Br J Gen Pract 2005; 55(518): 677-83.

[PMID: 16176734]

[15] Alonso-Sardón M, Iglesias-de-Sena H, Sáez-Lorenzo M, Chamorro Fernández AJ, Salvat-Puig J, Mirón-Canelo JA. B-learning training in the certification of causes of death. J Forensic Leg Med 2015; 29: 1-5. [http://dx.doi.org/10.1016/j.jflm.2014.10.003] [PMID: 25572076]

[16] World Health Organization. (2019) ICD-11 For Mortality and Morbidity Statistics, 2019 (ICD-11 MMS) (Version:04/2019)..
Available from: https://icd.who.int/browse11/1-m/en\#/?view=G0

[17] Turnock BJ. Public Health. $5^{\text {nd }}$. Jones \& Bartlett Publishers. 2012.

[18] National Office of Vital Statistics. Leading causes of death: United States and each state, 1949 Vital statistics - Special reports, national summaries; 36:(20). Washington, DC: Public Health Service 1952.

[19] Heron MP. Deaths: Leading causes for 2015; National Vital Statistic Reports. Cent Dis Control Prev 2017; 66(5): 1-76.

[20] State Planning Organization Statistics and Research Department, (2018). Statistical Yearbook. State Planning Organization: TRNC. URL. Available from: http://www.devplan.org/Frame-eng.html

[21] Bogdanović MD, Marić GD, Pekmezović TD, Alempijević ĐM. Evaluation of coding ill-defined and unknown causes of death in the Republic of Serbia. J Forensic Leg Med 2019; 62: 34-9.

[http://dx.doi.org/10.1016/j.jflm.2018.12.009] [PMID: 30639853]

[22] Özdemir R, Dinç H. G, Rao C, Sözmen MK, Ünal B. An evaluation of cause-of-death trends from recent decades based on registered deaths in Turkey. Public Health 2017; 151: 121-30. [http://dx.doi.org/10.1016/j.puhe.2017.07.006] [PMID: 28787632]

[23] Akturan S, Gümüş B, Özer Ö, et al. Death rates and causes of death in turkey between 2009 and 2016 based on tuik data. Konuralp Medical Journal 2019; 11(1): 9-16.

[http://dx.doi.org/10.18521/ktd.506407]

[24] Schünemann J, Strulik H, Trimborn T. The gender gap in mortality: How much is explained by behavior? J Health Econ 2017; 54: 79-90. [http://dx.doi.org/10.1016/j.jhealeco.2017.04.002] [PMID: 28478344]

[25] Regan JC, Partridge L. Gender and longevity: Why do men die earlier than women? Comparative and experimental evidence. Best Pract Res Clin Endocrinol Metab 2013; 27(4): 467-79. [http://dx.doi.org/10.1016/j.beem.2013.05.016] [PMID: 24054925]

[26] Crimmins EM, Shim H, Zhang YS, Kim JK. Differences between men and women in mortality and the health dimensions of the morbidity process. Clin Chem 2019; 65(1): 135-45.

[http://dx.doi.org/10.1373/clinchem.2018.288332] [PMID: 30478135]

[27] Brooke HL, Talbäck M, Hörnblad J, et al. The Swedish cause of death register. Eur J Epidemiol 2017; 32(9): 765-73.

[http://dx.doi.org/10.1007/s10654-017-0316-1] [PMID: 28983736]

[28] Rey G, Bounebache K, Rondet C. Causes of deaths data, linkages and big data perspectives. J Forensic Leg Med 2018; 57: 37-40. [http://dx.doi.org/10.1016/j.jflm.2016.12.004] [PMID: 29801950]

[29] Reid A, Garrett E, Dibben C, Williamson L. 'A confession of ignorance': Deaths from old age and deciphering cause-of-death statistics in Scotland, 1855-1949. Hist Fam 2015; 20(3): 320-44. [http://dx.doi.org/10.1080/1081602X.2014.1001768] 26900320]

[30] Knopman DS. Dementia and cerebrovascular disease. Mayo Clin Proc 2006; 81(2): 223-30.

[http://dx.doi.org/10.4065/81.2.223] [PMID: 16471078]

[31] MacDorman MF, Declercq E, Thoma ME. Trends in Texas maternal mortality by maternal age, race/ethnicity and cause of death, 2006-2015. Birth 2018; 45(2): 169-77.

[http://dx.doi.org/10.1111/birt.12330] [PMID: 29314209]

[32] Loney T, Nagelkerke NJ. The individualistic fallacy, ecological studies and instrumental variables: A causal interpretation. Emerg Themes Epidemiol 2014; 11(1): 18. [http://dx.doi.org/10.1186/1742-7622-11-18] [PMID: 25745504]

\section{(c) 2020 Artac Ozdal and Behlul et al.}

This is an open access article distributed under the terms of the Creative Commons Attribution 4.0 International Public License (CC-BY 4.0), a copy of which is available at: https://creativecommons.org/licenses/by/4.0/legalcode. This license permits unrestricted use, distribution, and reproduction in any medium, provided the original author and source are credited. 